Review

\title{
Development of Next Generation Stevia Sweetener: Rebaudioside M
}

\author{
Indra Prakash $^{1}{ }^{1}$, Avetik Markosyan ${ }^{2}$ and Cynthia Bunders ${ }^{1}$ \\ 1 The Coca-Cola Company, Atlanta, GA 30313, USA; E-Mail: cbunders@ coca-cola.com \\ 2 PureCircle Limited, Lengkuk Teknologi, 71760 Bandar Enstek, Negeri Sembilan, Malaysia; \\ E-Mail: avetik@purecircle.com
}

* Author to whom correspondence should be addressed; E-Mail: iprakash@coca-cola.com; Tel.: +1-404-676-3007; Fax: +1-404-598-2602.

Received: 21 January 2014; in revised form: 18 February 2014 / Accepted: 19 February 2014 / Published: 27 February 2014

\begin{abstract}
This work aims to review and showcase the unique properties of rebaudioside $\mathrm{M}$ as a natural non-caloric potential sweetener in food and beverage products. To determine the potential of rebaudioside $\mathrm{M}$, isolated from Stevia rebaudiana Bertoni, as a high potency sweetener, we examined it with the Beidler Model. This model estimated that rebaudioside M is 200-350 times more potent than sucrose. Numerous sensory evaluations of rebaudioside M's taste attributes illustrated that this steviol glycoside possesses a clean, sweet taste with a slightly bitter or licorice aftertaste. The major reaction pathways in aqueous solutions ( $\mathrm{pH} 2-8$ ) for rebaudioside $\mathrm{M}$ are similar to rebaudioside A. Herein we demonstrate that rebaudioside $\mathrm{M}$ could be of great interest to the global food industry because it is well-suited for blending and is functional in a wide variety of food and beverage products.
\end{abstract}

Keywords: specifications; rebaudioside M; rebaudioside A; purification; stability; food application; sweetener blends

\section{Introduction}

High-purity rebaudioside $\mathrm{M}$ (also known as rebaudioside $\mathrm{X}$ ), is a natural non-calorie sweetener being commercialized jointly by PureCircle Limited and The Coca-Cola Company for food and beverage use. Rebaudioside $\mathrm{M}$ is one of the minor sweet components of Stevia rebaudiana Bertoni, a South American plant. It is a glycoside of the ent-kaurene diterpenoid aglycone known as steviol, and 
is found in nature accompanied by at least ten other sweet-tasting steviol glycosides [1-3]. Stevia sweeteners have been approved for use as a sweetener in a number of countries, including US, EU, Japan, China, Brazil and other countries [4].

\section{Discovery of Rebaudioside $M$}

The leaves of Stevia rebaudiana Bertoni have been used by the natives of Paraguay to sweeten beverages for centuries [5]. The plant is the source of a number of sweet ent-kaurene diterpenoid glycosides (Figure 1, Table 1), but the major sweet constituents are rebaudioside A (1) and stevioside (8).

Figure 1. Backbone figure of Stevia sweeteners.

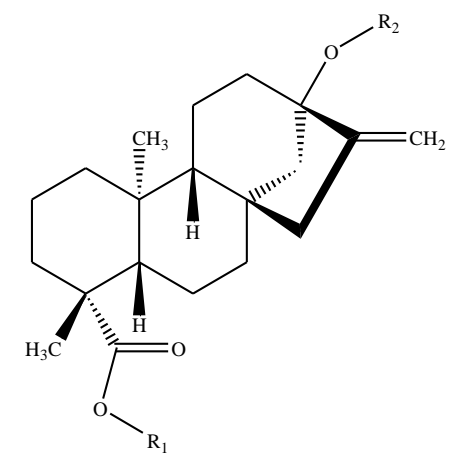

Table 1. R-groups, molecular formulas, molecular weights and potencies of the Stevia sweeteners.

\begin{tabular}{|c|c|c|c|c|c|c|}
\hline \multirow{2}{*}{ Sweetener } & \multirow{2}{*}{$\begin{array}{c}\text { Reference } \\
\text { Number } \\
\text { in Text }\end{array}$} & \multicolumn{2}{|c|}{ R-Groups in Backbone Figure Above } & \multirow[b]{2}{*}{ Formula } & \multirow{2}{*}{$\begin{array}{c}\text { Molecular } \\
\text { Weight (g/mol) }\end{array}$} & \multirow[b]{2}{*}{ Potency * } \\
\hline & & $\mathbf{R}_{1}$ & $\mathbf{R}_{2}$ & & & \\
\hline Rebaudioside A & 1 & $\beta$-glc- & $(\beta-\text { glc })_{2}-\beta-$ glc- & $\mathrm{C}_{44} \mathrm{H}_{70} \mathrm{O}_{23}$ & 967.01 & 200 \\
\hline Rebaudioside B & 2 & $\mathrm{H}$ & $(\beta \text {-glc })_{2}-\beta$-glc- & $\mathrm{C}_{38} \mathrm{H}_{60} \mathrm{O}_{18}$ & 804.88 & 150 \\
\hline Rebaudioside C & 3 & $\beta$-glc- & $(\beta$-glc, $\alpha$-rha- $)-\beta$-glc- & $\mathrm{C}_{44} \mathrm{H}_{70} \mathrm{O}_{22}$ & 951.01 & 30 \\
\hline Rebaudioside D & 4 & $\beta$-glc- $\beta$-glc- & $(\beta \text {-glc })_{2}-\beta$-glc- & $\mathrm{C}_{50} \mathrm{H}_{80} \mathrm{O}_{28}$ & 1129.15 & 221 \\
\hline Rebaudioside E & 5 & $\beta$-glc- $\beta$-glc- & $\beta$-glc- $\beta$-glc- & $\mathrm{C}_{44} \mathrm{H}_{70} \mathrm{O}_{23}$ & 967.01 & 174 \\
\hline Rebaudioside F & 6 & $\beta$-glc- & $(\beta$-glc, $\beta$-xyl)- $\beta$-glc- & $\mathrm{C}_{43} \mathrm{H}_{68} \mathrm{O}_{22}$ & 936.99 & 200 \\
\hline Rebaudioside M & 7 & $(\beta \text {-glc })_{2}-\beta$-glc- & $(\beta \text {-glc })_{2}-\beta$-glc- & $\mathrm{C}_{56} \mathrm{H}_{90} \mathrm{O}_{33}$ & 1291.3 & 250 \\
\hline Stevioside & 8 & $\beta$-glc- & $\beta$-glc- $\beta$-glc- & $\mathrm{C}_{38} \mathrm{H}_{60} \mathrm{O}_{18}$ & 804.88 & 210 \\
\hline Steviolbioside & 9 & $\mathrm{H}$ & $\beta$-glc- $\beta$-glc- & $\mathrm{C}_{32} \mathrm{H}_{50} \mathrm{O}_{13}$ & 642.73 & 90 \\
\hline Rubusoside & 10 & $\beta$-glc- & $\beta$-glc- & $\mathrm{C}_{32} \mathrm{H}_{50} \mathrm{O}_{13}$ & 642.73 & 114 \\
\hline Dulcoside A & 11 & $\beta$-glc- & $\alpha$-rha- $\beta$-glc- & $\mathrm{C}_{38} \mathrm{H}_{60} \mathrm{O}_{17}$ & 788.87 & 30 \\
\hline
\end{tabular}

glc = glucose; rha = rhamnose; $x y l=$ xylose $*$ Potency from $[1,6,7]$.

In our continuing research to discover a natural non-caloric sweetener, we have focused on minor steviol glycosides and found a novel minor steviol glycoside, rebaudioside M (7) that is more potent, has higher sweetness intensity, and very slight licorice or bitter aftertaste than other steviol glycosides.

Work to elucidate the chemical structures of $S$. rebaudiana sweeteners began in the early twentieth century, but proceeded slowly. The structures 1 and $\mathbf{8}$ (Figure 2) were not fully determined until 1970 [8-10]. During the 1970s, additional sweet components, including rebaudiosides A-E, were 
isolated from $S$. rebaudiana leaves and characterized by Osamu Tanaka and co-workers at Hiroshima University in Japan [11]. Several novel steviol glycosides have been reported from the commercial extracts of the leaves of $S$. rebaudiana in the last few years [6,12-19]. Recently we reported the structure elucidation and isolation of rebaudioside M from S. rebaudiana Bertoni (7) [20,21]. In addition, rebaudioside $M$ received a Letter of No Objection concerning its Generally Recognized as Safe (GRAS) status from US FDA [22].

Figure 2. Comparison of the chemical structures of rebaudioside A (1), stevioside (8) and rebaudioside $\mathrm{M}(\mathbf{7})$.
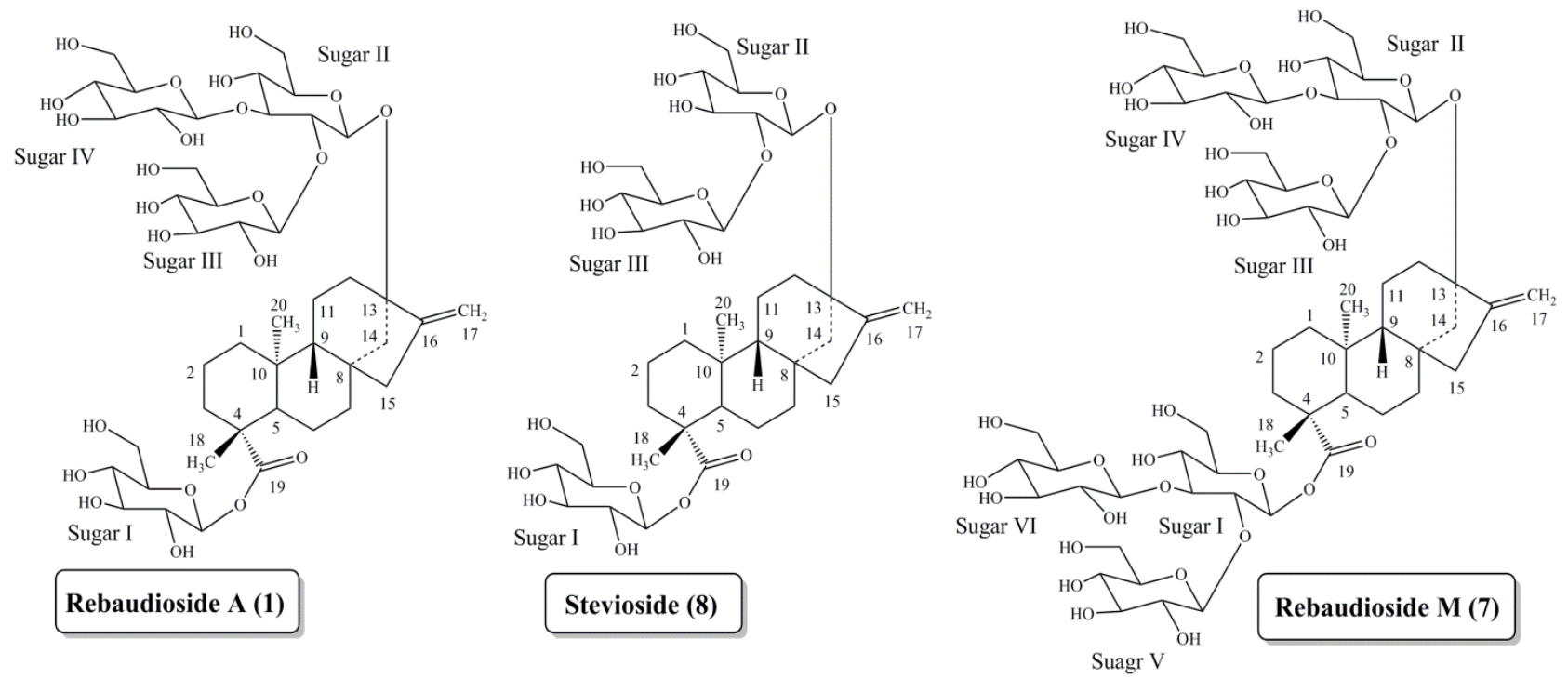

\section{Experimental Section}

\subsection{Purification of Rebaudioside $M$}

Rebaudioside M (7) was obtained from Stevia rebaudiana Bertoni cultivar AKH L1 leaves [23]. Two kilograms of $S$. rebaudiana leaves were extracted by $40 \mathrm{~L}$ water at $40{ }^{\circ} \mathrm{C}$ for two hours. The filtrate was separated and treated with a flocculant (calcium oxide) to remove the mechanical particles, proteins, polysaccharides and coloring agents. The resulting precipitate was separated by filtration and the filtrate was deionized by Amberlite FCP22 $\left(\mathrm{H}^{+}\right)$and Amberlite FPA53 $\left(\mathrm{OH}^{-}\right)$ion-exchange resins. The deionized filtrate was fractionated by seven columns, packed with Diaion HP20 (Mitsubishi Chemical, Japan). The columns with higher rebaudioside $\mathrm{M}$ content were eluted using aqueous ethanol. The obtained glycoside eluate was treated with activated carbon, deionized, evaporated and dried in vacuo. The obtained material was recrystallized twice from aqueous methanol to afford about $1.1 \mathrm{~g}$ of rebaudioside $\mathrm{M}$ with $>98 \%$ purity by HPLC [21]. The highly purified stevia extract meets the international Joint Expert Committee on Food Additives (JECFA) purity requirement for steviol glycosides, which requires $\geq 95 \%$ total steviol glycosides [7]. 


\subsection{Properties of Rebaudioside $M$}

Pure rebaudioside M (7) (>95\%) crystallizes out as a crystalline form which is slightly soluble in water $\left(0.1 \mathrm{~g} / 100 \mathrm{~mL}\right.$ at $25{ }^{\circ} \mathrm{C}$ in $\left.5 \mathrm{~min}\right)$ and in ethanol. Its amorphous material has a solubility of $1.1 \%-1.3 \%$ in water at $25^{\circ} \mathrm{C}$. The thermodynamic equilibrium solubility in water is $0.26 \%$ at $25^{\circ} \mathrm{C}$ [24].

\subsection{Stability of Rebaudioside $M$}

As a dry powder, rebaudioside M (7) is stable for at least one year at ambient temperature and under controlled humidity conditions. In solution, it is most stable in $\mathrm{pH} 4-8$ and noticeably less stable below $\mathrm{pH}$ 2. As expected, the stability decreases with increasing temperature. Its stability is very similar to rebaudioside A [25].

In aqueous solutions ( $\mathrm{pH} 2-8$ ), the major reaction pathways leading to loss of rebaudioside $\mathrm{M}$ are as follows (Figure 3): isomerization of the $\mathrm{C}-16$ olefin to form the $\mathrm{C}-15$ isomer (12), hydration of the C-16 olefin to yield compound $\mathbf{1 3}$, hydrolysis of the glycosidyl ester at C-19 to form compound $\mathbf{2}$, and isomerization of the $\mathrm{C}-16$ olefin to form the $\mathrm{C}-15$ isomer in 2 to form compound 16. All of these compounds $(2,12,13$ and 16) are sweet. Compound 12 is sweeter than compounds 2, 13 and 16, and has similar taste properties as that of compound 7. Upon metabolism in vitro, rebaudioside M (7), just like rebaudioside A (1), is primarily converted to its aglycone steviol (14) and to the glucuronic acid of steviol, generally known as steviol glucuronide (15) [26].

Rebaudioside M (7) has similar stability as that of rebaudioside A (1) in both low and high $\mathrm{pH}$ applications. In heat-processed beverages, such as flavored ice-tea, juices, sport drinks, flavored milk, drinking yogurt and non-acidified teas, the sweetener shows good stability during High TemperatureShort Time heat processing and on subsequent product storage [27].

\subsection{Sensory Panel for Rebaudioside $M$ and Other Sweeteners}

To determine the sensory attributes of rebaudioside M (7) we compared it to rebaudioside A (1), which possesses well defined characteristics. In addition, blending techniques with rebaudioside $\mathrm{M}$ and other sweetener were examined to demonstration the potential of this sweetener. Herein we describe our sensory panel testing. Concentration-response $(\mathrm{C} / \mathrm{R})$ function work was done with 60 in-house trained panelists (Two-Alternative Forced Choice, 2-AFC method), with the panelists specifying which of the two samples was perceptually sweeter. Sweetener blend work was done with 8-10 descriptive analysis (DA) panelists that have been highly trained. DA panelists go through 10-12 weeks of extensive descriptive training. The panel was calibrated at the beginning of each test session. In addition the panel also received anchor references representing early (sucrose), middle (aspartame) and late (thaumatin) AT every three test samples. Samples were given to the panel members sequentially and coded with triple digit numbers. The order of sample presentation was randomized to avoid the order of presentation bias. Water and unsalted crackers were provided in order to cleanse the palate. The panel members were asked to rate different attributes including sweetness onset, total sweetness, rounded sweetness, bitterness, acidity, leafy note, licorice, astringency, mouthfeel, mouth coating, sweet lingering, and bitter lingering. Samples were rated on a scale of zero (0) to ten (10), with zero indicating immediate onset, no intensity, watery/low viscosity, or very sharp peak, and ten indicating 
very delayed onset, high intensity, thick/high viscosity, or very round peak. One-way single factor ANOVA was used to analyze sensory results, where $\alpha=0.05$.

Figure 3. Major pathways of degradation of rebaudioside M (7) under hydrolytic conditions.
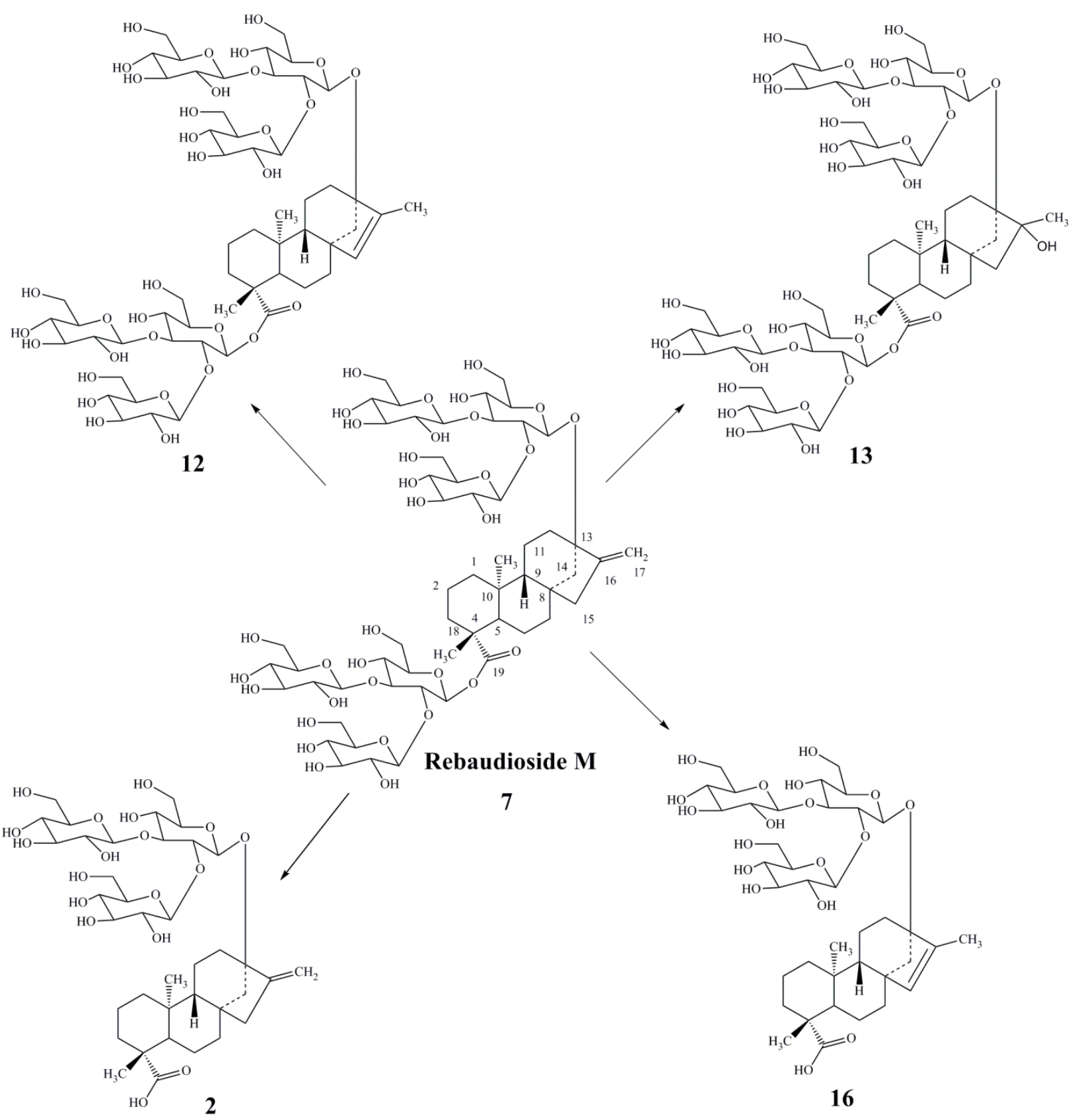


\section{Results and Discussion}

\subsection{Rebaudioside M Sensory Attributes}

To decipher the potential of rebaudioside $M$ as a high potency sweetener, we first examined it against sucrose with the Beidler Model (Law of Mass Action) [28]. We used several reference samples of $2.5 \%, 5.0 \%, 7.5 \%$ and $10.0 \%$ sucrose solutions. Since sweetness potency is strongly dependent on sucrose equivalency level for all high potency sweeteners (HPS), it is important to state the sucrose equivalency (SE) level at which sweetness potency has been determined. Sweetness potency is also system dependent and therefore, it is important to define the medium (e.g., water, phosphoric acid at $\mathrm{pH} 2.5$, etc.). The concentration-response $(C / R)$ function in water determined for rebaudioside $\mathrm{M}$ is $R=14.2 \times C /(265+C)$ at $4{ }^{\circ} \mathrm{C}$. Given the high $R_{\mathrm{m}}$ of 14.2 , rebaudioside M can be used both in single and blended sweetener applications. From the $C / R$ function the potency of water $\left(\mathrm{P}_{\mathrm{w}}\right)$ is $\mathrm{P}_{\mathrm{w}}(5)=347$ and $\mathrm{P}_{\mathrm{w}}(10)=159$ (Figure 4). This model estimates that the potency of rebaudioside $\mathrm{M}$ is $200-350$ times that of sucrose.

Figure 4. Concentration-response curves of rebaudioside $\mathrm{M}(7)$ in water at $4{ }^{\circ} \mathrm{C}$.

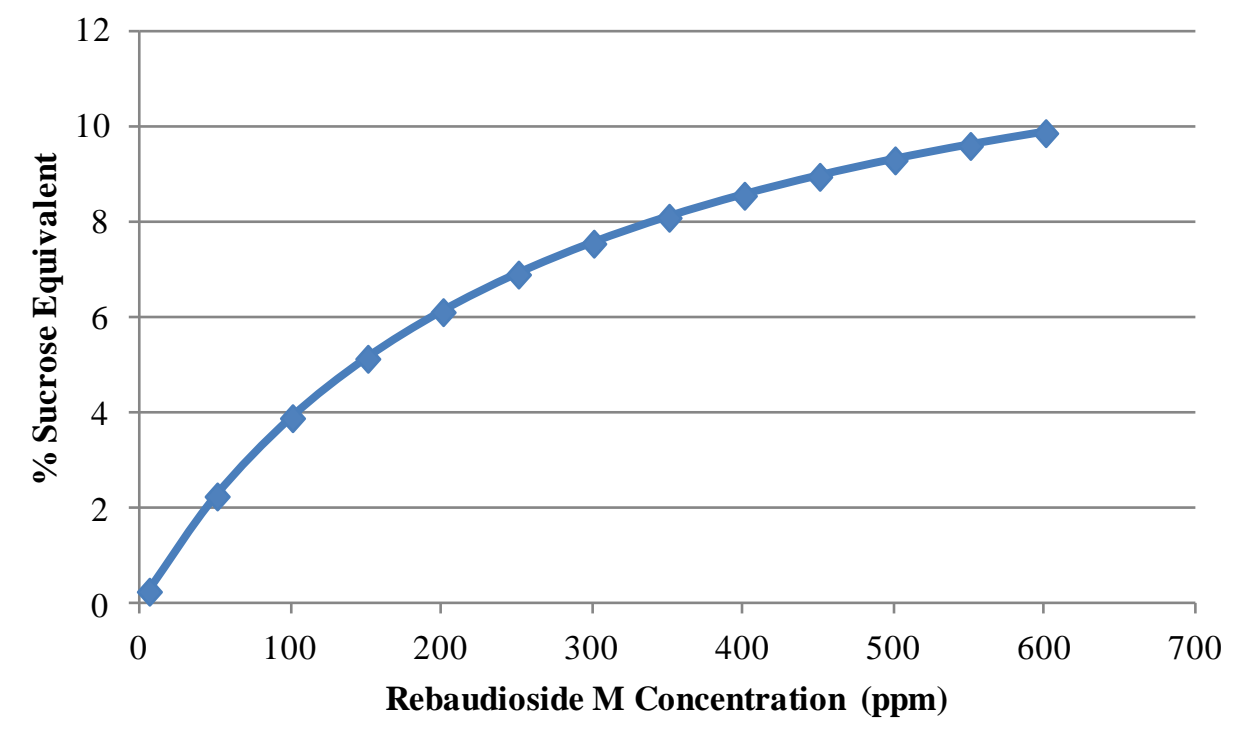

To enlist a broader picture of rebaudioside M (7) sensory attributes, we compared it to rebaudioside A (1). To compare the sensory attributes between rebaudioside M (7) and rebaudioside A (1), iso-sweet samples (8\% sucrose equivalent sweetness) were made with filtered water as shown in Table 2. An $8 \%$ sugar solution in water was used as a control. The same concentrations of rebaudioside A and rebaudioside $\mathrm{M}$ were also used in acidified solutions (250 ppm citric acid, $\mathrm{pH} \mathrm{3.2)}$ and an $8 \%$ sugar solution acidified with citric acid was used as a standard. As described in Section 2.4, sensory panelist examined the two sweeteners and a spider plot was extracted (Figure 5).

In water solution, rebaudioside $M(7)$ showed (Figure 5A) the reduced perception of bitterness, astringency, bitter lingering compared to rebaudioside A (1), and similar sweetness intensity. A much higher sweetness perception of rebaudioside $M$ than rebaudioside $A$ in acidified water was established in Figure 5B. Rebaudioside M displayed faster sweetness onset, reduced non-sweet taste (bitterness, sour, astringency) and bitterness lingering. 
Table 2. Iso-sweet solutions of rebaudioside A (1) and rebaudioside M (7) in water.

\begin{tabular}{ccc}
\hline Solutions & $\mathbf{( \% )}$ & $\mathbf{( \% )}$ \\
\hline Water & 99.95 & 99.95 \\
Rebaudioside A 97 (dry basis) & $0.0510 \mathrm{~g}$ & \\
Rebaudioside M (dry basis) & & $0.0423 \mathrm{~g}$ \\
\hline
\end{tabular}

Figure 5. Comparison of sensory attributes of rebaudioside $M$ (Reb $M$ ) (7) and rebaudioside A (Reb A) (1) in water (A). Comparison of sensory attributes of rebaudioside $\mathrm{M}$ and rebaudioside $\mathrm{A}$ in acidified water $(\mathbf{B})$.

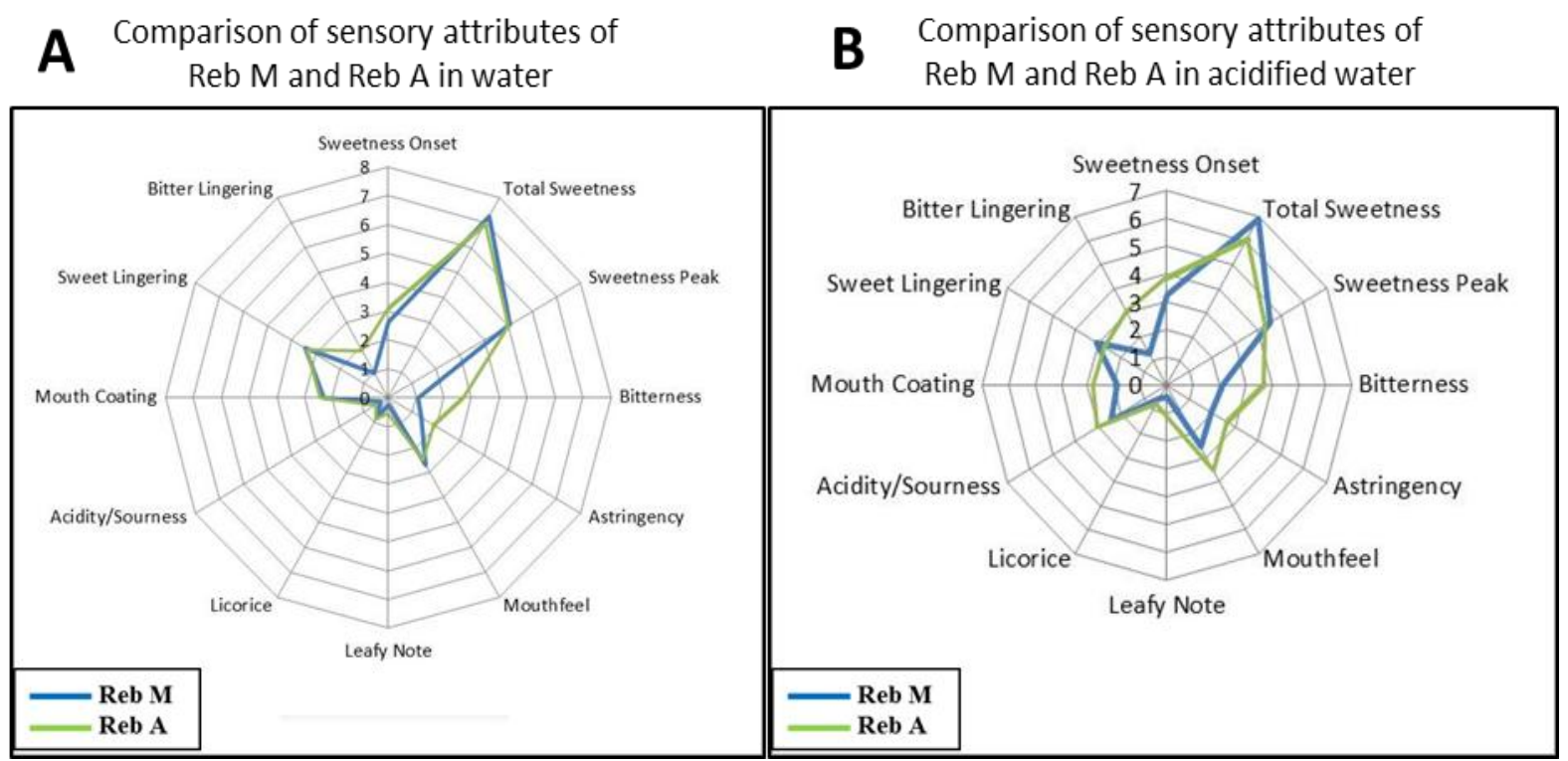

To expand the descriptive taste profile of rebaudioside $\mathrm{M}(7)$ a set of trained panelist (Section 2.4) examined $10 \%$ sucrose, aspartame at $531 \mathrm{mg} / \mathrm{L}$, and rebaudioside $\mathrm{M}$ at $563 \mathrm{mg} / \mathrm{L}$ in water at $4{ }^{\circ} \mathrm{C}$. Unlike other steviol glycosides including rebaudioside A (1), trained descriptive panel did not detect any significant bitter or licorice off taste when evaluated rebaudioside $\mathrm{M}$ in water at approximately 10\% SE levels (Figure 6). Rebaudioside $\mathrm{M}$ had a slightly more intense sweet aftertaste then aspartame. Based on our study rebaudioside $M$ and aspartame have similar high potency sweetener profiles.

Sweetness temporal profiles demonstrate changes in perception of sweetness over time. This property is a key to a sweetener's utility in foods and beverages, and is complementary to its flavor profile. Every sweetener exhibits a characteristic Appearance Time (AT) and Extinction Time (ET). Most high-potency sweeteners, in contrast to carbohydrate sweeteners, display prolonged ET. This can be beneficial in some products such as chewing gum, where prolonged sweetness is desirable.

With these samples in hand panelist examined the AT and ET of the three sweeteners described in Figure 6. The sweetness temporal profiles of aspartame at $531 \mathrm{mg} / \mathrm{L}$, rebaudioside $\mathrm{M}$ at $563 \mathrm{mg} / \mathrm{L}$, and sucrose at $10 \%$ in water at room temperature were compared over a period of $3 \mathrm{~min}$ (samples were swallowed at $5 \mathrm{~s}$ ). The AT maximum was the shortest for sucrose, slightly longer for aspartame and longest for rebaudioside M. The ET was longest for rebaudioside M, followed by aspartame and then sucrose. 
Figure 6. Descriptive taste profile of rebaudioside $\mathrm{M}(7)$ at $563 \mathrm{mg} / \mathrm{L}$, aspartame at $531 \mathrm{mg} / \mathrm{L}$ and sucrose at $10 \%$ in water.

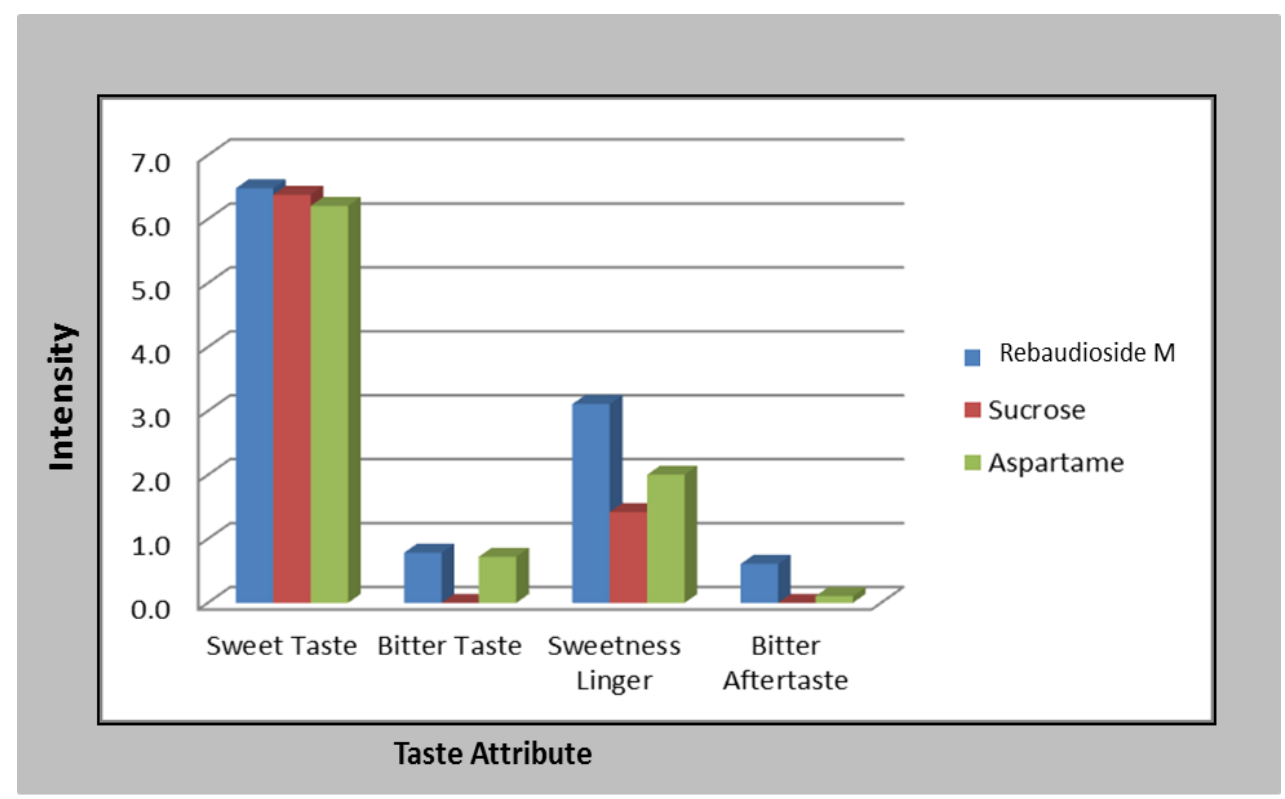

\subsection{Blending}

Blending of certain sweeteners (nutritive as well as non-nutritive) is often found to result in sweetness synergy. Such blends are also generally advantaged by improvements in flavor and temporal profiles as well as cost reductions in sweetener system and, often, improvement in stability [29-33].

To study the interactions between rebaudioside $M(7)$ and other natural ingredients, blends were made with rebaudioside A (1), rebaudioside D (4), rebaudioside B (2), and erythritol at various concentrations in acidified water and sensory evaluation were performed.

Figure 7 illustrates the average response from sensory panelists that tasted the acidified solution with rebaudioside $\mathrm{M}(300 \mathrm{ppm})$ and rebaudioside A (100 ppm) or rebaudioside D (100 ppm) blends. The di-blends showed improvement in total sweetness, overall sweetness profile (peak), and leafy note. The blend with rebaudioside $\mathrm{M}$ and rebaudioside $\mathrm{D}$ showed higher improvement in sweetness intensity, overall sweetness profile, bitter lingering and sweet lingering.

The average response from sensory panelists that tasted the acidified solution with rebaudioside $\mathrm{M}$ and rebaudioside B blends (100 ppm or $50 \mathrm{ppm}$ ) is presented in Figure 8. The rebaudioside $\mathrm{M}$ and rebaudioside $\mathrm{B}$ di-blend exhibited additional rounded sweetness profile with slight improvement in sweetness intensity, onset and bitterness perception. 
Figure 7. Sensory profile of di-blends of rebaudioside $M(7)$ and rebaudioside A (1) or rebaudioside D (4) in acidified water.

Di-blends of Reb M with Reb A or Reb D in Acidified Water

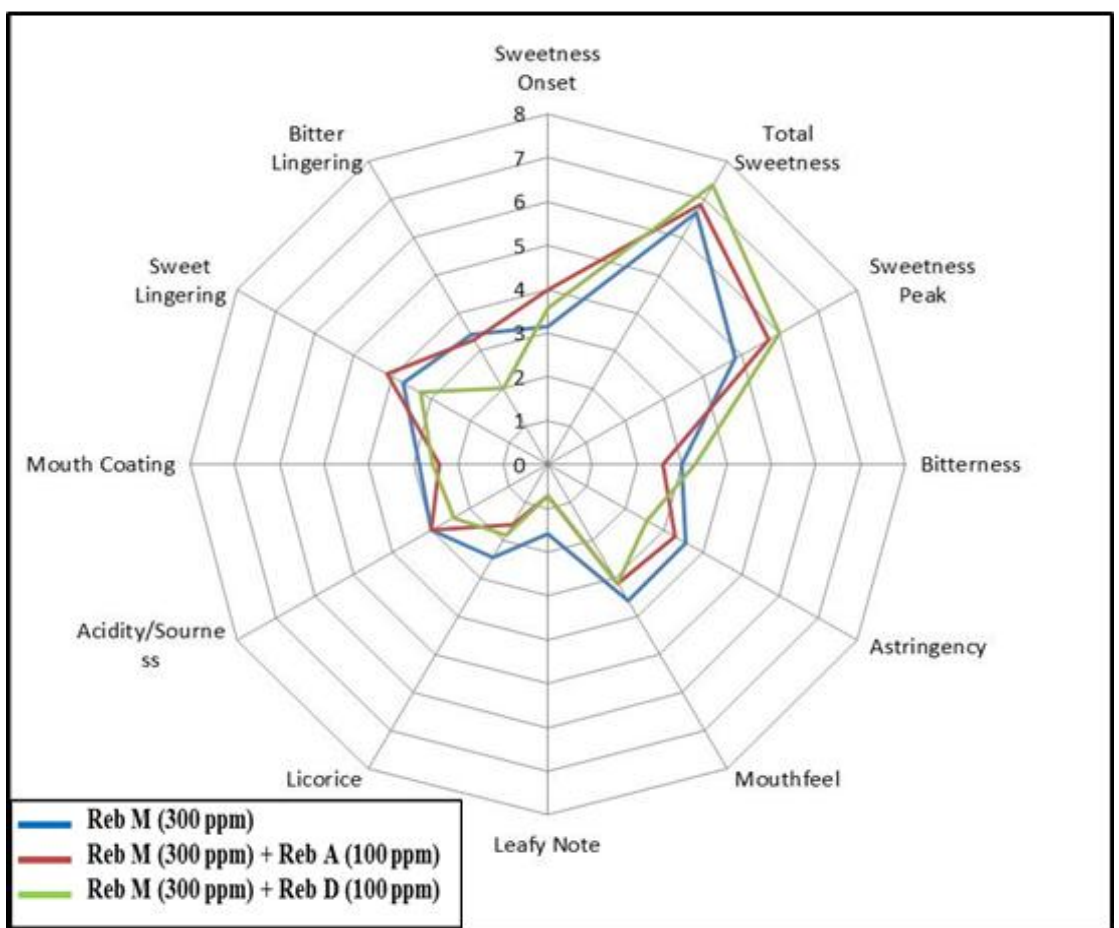

Figure 8. Sensory profile of di-blends of rebaudioside $M(7)$ and rebaudioside $B$ in acidified water.

Di-blends of Reb M with Reb B in Acidified Water

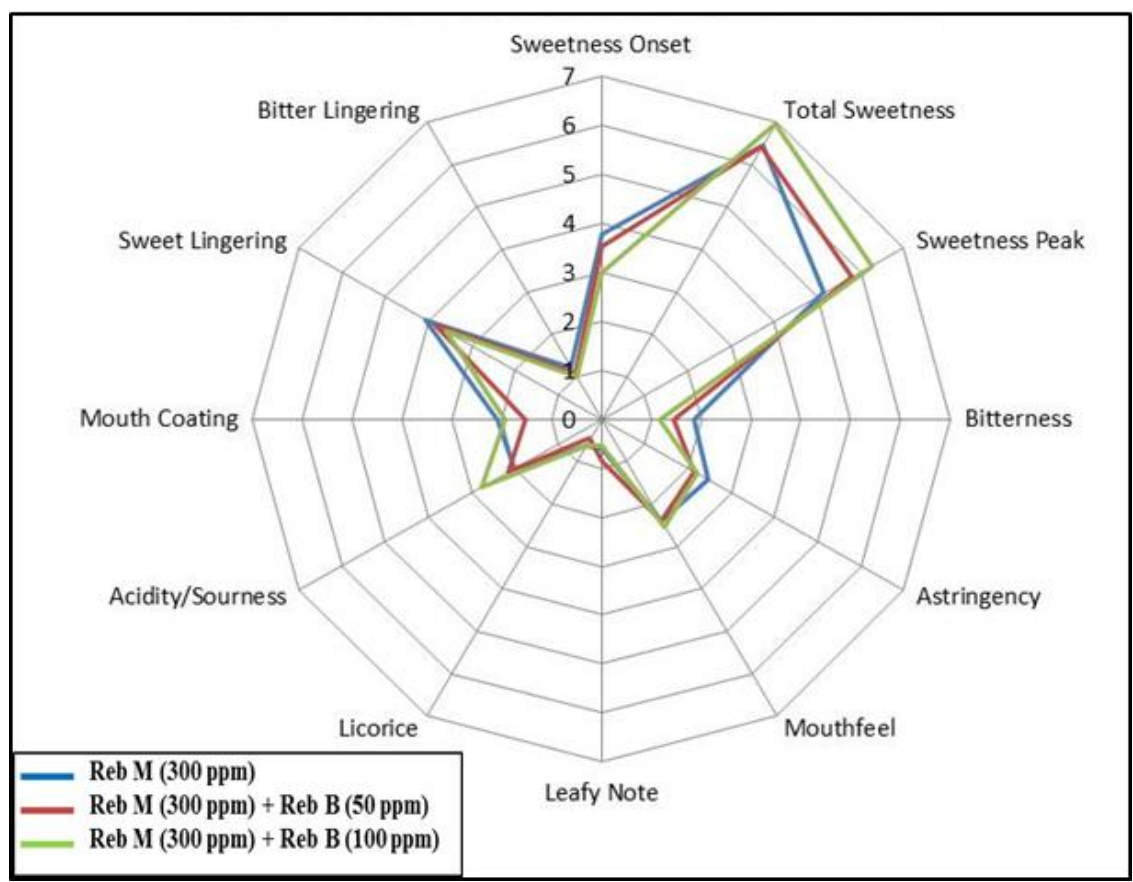

The taste description of rebaudioside $M$ and erythritol is displayed in Figure 9 based on the average response from sensory panelists that tasted the acidified solution di-blend. The blend with erythritol 
helps in reducing acidity, bitterness, astringency and bitter lingering. At a higher level (above 1\%, 100 ppm) erythritol contributes additional sweetness, rounded sweet profile and earlier onset.

Figure 9. Sensory profile of di-blends of rebaudioside M (7) and erythritol in acidified water.

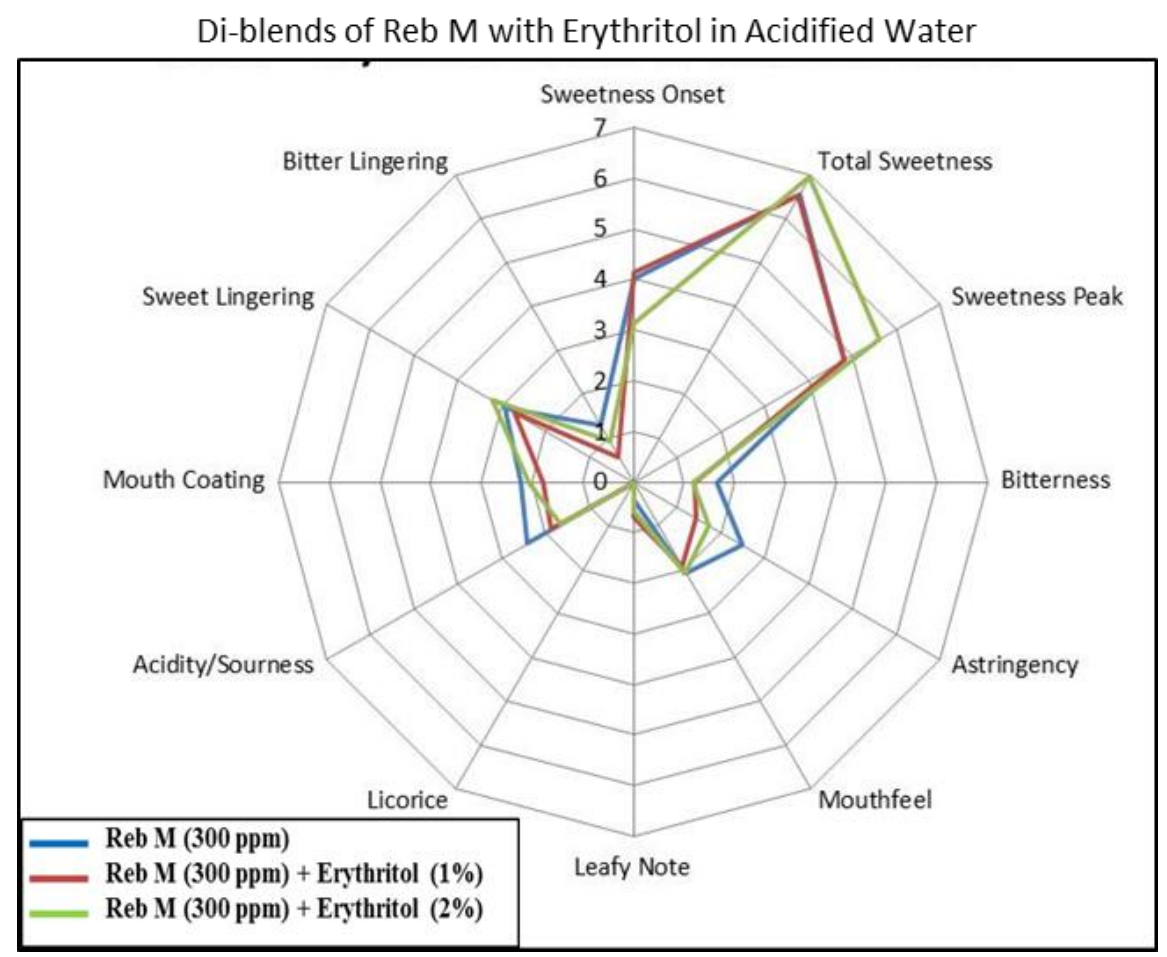

Rebaudioside M (7) can be used as a single sweetener system in sparkling beverages and commonly employed in blends with a number of sweeteners. A wide range of both non-caloric and caloric sweeteners are suitable partners for rebaudioside $\mathrm{M}$. This work illustrates a few of the possibilities for di-blend non-caloric sweeteners and how they alter sensory attributes. In addition, a blend where rebaudioside $\mathrm{M}$ contributes $20 \%-80 \%$ of the sweetness, and sucrose provides the rest, exhibits flavor and temporal profiles very close to that of sugar (short AT). Such blends of natural sweeteners offer (i.e., rebaudioside $\mathrm{M}$ and sucrose) substantial energy reduction over sucrose alone. Sweet tasting amino acids such as glycine, alanine, glutamine, proline and serine as well as salts such as sodium chloride and potassium chloride also improve the taste of rebaudioside $\mathbf{M}$ [21]. These blends also permit the formulations of good-tasting, natural, blended sweetener systems with lower energy content than carbohydrate sweeteners alone.

\subsection{Food Application}

The functionality and stability of rebaudioside $M(7)$ were demonstrated with a three-dimensional food matrix model representing the intended conditions of use in foods [34]. Based on experience with rebaudioside $\mathrm{A}$ (1), the key factors likely to affect rebaudioside $\mathrm{M}$ stability in product were considered to be product moisture, process temperature, and product $\mathrm{pH}$.

Products comprised of carbonated beverages, still non-alcoholic beverages, table-top sweetener formulations, chewing gum and yogurt. All products were packed, stored (mostly at $25{ }^{\circ} \mathrm{C}$ and $60 \%$ relative humidity) and evaluated at intervals using both chemical (HPLC) and sensory analyses. 
Sweetness of these products was assessed using panels consisting of 35 to 50 persons. Samples were evaluated using a five-point scale of categories ranging from 5 (much too sweet) to 1 (not at all sweet). Samples were considered satisfactory if at least $80 \%$ of the panelists rated the sweetness in category 3 (just about right) or above.

In this study key findings were determined to provide insight of the sweetness properties of rebaudioside $\mathrm{M}$ (7) in a wide variety of products. In the category of soft drinks (both carbonated and still) cola and lemon-lime, sweetened with rebaudioside $\mathrm{M}$, remained acceptably sweet throughout 26 weeks storage. For comparison, most soft drinks are consumed within 16 weeks of production. Concerning table-top sweetener, rebaudioside $M$ was tested in a number of formulations and all were stable for at least 52 weeks. Rebaudioside $M$ was considered stable and functional in chewing gum for 26 weeks. Plain yogurt was evaluated, it was deemed to have no significant loss of sweetness during measured pasteurization ( $190^{\circ} \mathrm{F}$ for $5 \mathrm{~min}$ ) and fermentation. Rebaudioside $\mathrm{M}$ was stable throughout a 6 week storage period $\left(40^{\circ} \mathrm{F}\right)$ in plain yogurt. Table 3 provides range concentrations of rebaudioside $\mathrm{M}$ for sweeten of various food and beverages.

Table 3. Typical rebaudioside $M$ (7) concentrations used to sweeten various foods and beverages.

\begin{tabular}{cc}
\hline Product & $\begin{array}{c}\text { Range }^{\text {a }} \\
(\mathbf{m g} / \mathbf{k g ~ o r ~} \mathbf{~ m g} / \mathbf{L})\end{array}$ \\
\hline Carbonated soft drinks & $100-600$ \\
Still beverages & $50-600$ \\
Powdered soft drinks (as is) & $200-2000$ \\
Tabletop (as is) & $800-4000$ \\
Bakery products & $200-1000$ \\
Dairy products & $150-1000$ \\
Chewing gum & $300-6000$ \\
Confections & $100-1000$ \\
Cereals & $200-1000$ \\
Edible gels & $200-1000$ \\
Nutraceuticals & $200-1000$ \\
Pharmaceuticals & $50-1000$ \\
\hline
\end{tabular}

a Typical concentration when used as a single sweetener. Concentrations may vary depending upon formulation, flavor, and target consumer.

\section{Conclusions}

Through numerous evaluations we have determined that rebaudioside $\mathrm{M}$ has many beneficial properties and abundant potential as a sweetener in beverage and food products. This work illustrates that rebaudioside $\mathrm{M}$ has the capability to provide zero calories and has a clean sweet taste with slight bitter or licorice aftertaste. Functional in a wide array of beverages and foods, it is also well-suited for blending with other non-calorie or carbohydrate sweeteners. The molecule is stable under dry conditions and its stability is similar to rebaudioside $\mathrm{A}$ in aqueous food systems. High-purity zero-calorie natural stevia extract is of great interest to the global food industry because its natural source appeals to many consumers. 


\section{Conflicts of Interest}

The authors declare no conflict of interest.

\section{References}

1. Kinghorn, A.D.; Kim, N.-C.; Kim, D.H.L. Terpenoid glycoside sweeteners. In Naturally Occurring Glycosides; Ikan, R., Ed., John Wiley \& Sons: New York, NY, USA, 1999; pp. 399-429.

2. Kinghorn, A.D.; Wu, C.D.; Soejarto, D.D. Stevioside. In Alternative Sweeteners, 3rd ed, Revised and Expanded; O’Brien Nabors, L., Ed.; Marcel Dekker: New York, NY, USA, 2001; pp. 167-183.

3. Carakostas, M.; Prakash, I.; Kinghorn, A.D.; Wu, C.D.; Soejarto, D.D. Steviol glycosides. In Alternative Sweeteners, 4th ed., Revised and Expanded; O'Brien Nabors, L., Ed.; Marcel Dekker: New York, NY, USA, 2012; pp. 159-180.

4. Kinghorn, A.D.; Soejarto, D.D. Current status of stevioside as a sweetening agent for human use. In Economics and Medicinal Plant Research; Wagner, H., Hikino, H., Farnsworth, N.R., Eds.; Academic Press: London, UK, 1985; Volume 1, pp. 1-52.

5. Lewis, W.H. Early uses of Stevia rebaudiana (Asteraceae) leaves as a sweetener in Paraguay. Econ. Bot. 1992, 46, 336-337.

6. Prakash, I.; DuBois, G.E.; Clos, J.F.; Wilkens, K.L.; Fosdick, L.E. Development of Rebiana, a natural, non-caloric sweetener. Food Chem. Toxicol. 2008, 46, S75-S82.

7. Steviol Glycosides. Prepared at the 73rd JECFA (2010) and Published in FAO JECFA Monographs 10 (2010), Superseding Specifications Prepared at the 69th JECFA (2008) and Published in FAO JECFA Monographs 5 (2008). An ADI of $0-4 \mathrm{mg} / \mathrm{kg}$ bw (Expressed as Steviol) Was Established at the 69th JECFA (2008). Available online: http://www.fao.org/ag/agn/jecfa-additives/specs/monograph10/additive-442-m10.pdf (accessed on 1 November 2013).

8. Kinghorn, A.D.; Soejarto, D.D. Intensely sweet compounds of natural origin. Med. Res. Rev. 1989, 9, 91-115.

9. Kinghorn, A.D.; Soejarto, D.D. Sweetening agents of plant origin. CRC Crit. Rev. Plant Sci. 1986, 4, 79-120.

10. Kinghorn, A.D.; Compadre, C.M. Less common high-potency sweeteners. In Alternative Sweeteners, 2nd ed., Revised and Expanded; O’Brien Nabors, L., Gelardi, R.C., Eds.; Marcel Dekker: New York, NY, USA, 1991; pp. 197-218.

11. Kohda, H.; Kasai, R.; Yamasaki, K.; Murakami, K.; Tanaka, O. New sweet diterpene glucosides from Stevia rebaudiana. Phytochemistry 1976, 15, 981-983.

12. Ohta, M.; Sasa, S.; Inoue, A.; Tamai, T.; Fujita, I.; Morita, K.; Matsuura, F. Characterization of novel steviol glycosides from leaves of Stevia rebaudiana Morita. J. Appl. Glycosci. 2010, 57, 199-209.

13. Chaturvedula, V.S.P.; Prakash, I. A new diterpene glycoside from Stevia rebaudiana. Molecules 2011, 15, 2937-2943. 
14. Chaturvedula, V.S.P.; Prakash, I. Structures of the novel diterpene glycosides from Stevia rebaudiana. Carbohydr. Res. 2011, 34, 1057-1060.

15. Chaturvedula, V.S.P.; Rhea, J.; Milanowski, D.; Mocek, U.; Prakash, I. Two minor diterpenoid glycosides from the leaves of Stevia rebaudiana. Nat. Prod. Commun. 2011, 6, 175-178.

16. Chaturvedula, V.S.P.; Clos, J.F.; Rhea, J.; Milanowski, D.; Mocek, U.; DuBois, G.E.; Prakash, I. Minor diterpene glycosides from the leaves of Stevia rebaudiana. Phytochem. Lett. 2011, 4 , 209-212.

17. Chaturvedula, V.S.P.; Mani, U.; Prakash, I. Structures of the novel $\alpha$-glucosyl linked diterpene glycosides from Stevia rebaudiana. Carbohydr. Res. 2011, 346, 2034-2038.

18. Prakash, I.; Campbell, M.; San Miguel, R.I.; Chaturvedula, V.S.P. Synthesis and sensory evaluation of ent-kaurane diterpene glycosides. Molecules 2012, 17, 8908-8916.

19. Prakash, I.; Campbell, M.; San Miguel, R.I.; Chaturvedula, V.S.P. Catalytic hydrogenation of the sweet principles of Stevia rebaudiana, rebaudiosde B, rebaudioside C and rebaudioside D and sensory evaluation of their reduced derivatives. Int. J. Mol. Sci. 2012, 13, 15126-15136.

20. Prakash, I.; Chaturvedula, V.S.P.; Markosyan, A. Isolation, characterization and sensory evaluation of a hexa $\beta$-D-glucopyranosyl diterpene from Stevia rebaudiana. Nat. Prod. Commun. 2013, 8, 1523-1526.

21. Prakash, I.; Markosyan, A.; Chaturvedula, V.S.P.; Campbell, M.; San Miguel, R.; Purkayastha, S.; Johnson, M. Methods for Purifying Steviol Glycosides and Uses of the Same. PCT Patent Application WO 2013/096420, 27 June 2013.

22. Agency Response Letter GRAS Notice No. GRN 000473. Purified Steviol Glycosides with Rebaudioside X (also Known as Rebaudioside M) as the Principal Component. Available online: http://www.fda.gov/Food/IngredientsPackagingLabeling/GRAS/NoticeInventory/ucm382202 (accessed on 1 June 2013).

23. Alvarez, E.R.B. Stevia Plant Named 'AKH L1'. Patent Application Number 20120090062, 12 April 2012.

24. Prakash, I.; Markosyan, A.; Chaturvedula, V.S.P.; Ma, G. The stability of rebaudioside M. 2013, Unpublished work.

25. Purkayastha, S.; Pugh, G.; Lynch, B.; Roberts, A.; Kwok, D.; Tarka, S.M. In virto metabolism of rebaudioside $\mathrm{B}, \mathrm{D}$, and $\mathrm{M}$ under anaerobic conditions: Comparison with rebaudioside A. Regul. Toxicol. Pharmacol. 2013, 68, 259-268.

26. Prakash, I.; Chaturvedula, V.S.P.; Markosyan, A. Structural characterization of the degradation products of minor natural sweet ditrpene glycoside rebaudioside $\mathrm{M}$ under acidic conditions. Int. J. Mol. Sci. 2014, 15, 1014-1025.

27. Lavia, A.; Hill, J. Sweeteners with Masked Saccharin Aftertaste. French Patent 2,087,843, 1972.

28. DuBois, G.E.; Walters, D.E.; Schiffman, S.S.; Warwick, Z.S.; Booth, B.J.; Pecore, S.D.; Gibes, K.; Carr, B.T.; Brands, L.M. ACS Symposium Series 450. In Sweeteners: Discovery, Molecular Design, and Chemoreception; Walters, D.E., Orthoefer, F.T., DuBois, G.E., Eds.; American Chemical Soceity: Washington, DC, USA, 1990; pp. 261-276.

29. Paul, T. Physical chemistry of foodstuffs. V. Degree of sweetness of sugars. Chemiker-Zeitung 1921, 45, 38-39. 
30. Schiffman, S.; Booth, B.; Carr, B.; Losee, M.; Sattely-Miller, E.; Graham, B. Investigation of synergism in binary mixtures of sweeteners. Brain Res. Bull. 1995, 38, 105-120.

31. Scott, D. Saccharin-Dipeptide Sweetening Compositions. British Patent 1,256,995, 1971.

32. Verdi, R.J.; Hood, L.L. Advantages of alternative sweetener blends. Food Technol. 1993, 47, 94-102.

33. Walters, E. High intensity sweetener blends. In Food Product Design; Weeks Publishing Co.: Northbrook, IL, USA, 1993.

34. Pariza, M.; Ponakala, S.; Gerlat, P.; Andress, S. Predicting the functionality of direct food additives. Food Technol. 1998, 52, 56-60.

(C) 2014 by the authors; licensee MDPI, Basel, Switzerland. This article is an open access article distributed under the terms and conditions of the Creative Commons Attribution license (http://creativecommons.org/licenses/by/3.0/). 